\title{
Food Consumption Pattern of Cauvery Delta Region of Tamil Nadu-An Application of Quadratic Almost Ideal Demand System (QUAIDS)
}

\author{
T. Arivelarsan ${ }^{1 *}$ and C. Sekar ${ }^{2}$ \\ ${ }^{1}$ Department of Agricultural Economics, Tamil Nadu Agricultural University, Coimbatore, Tamil Nadu, India \\ ${ }^{2}$ Imayam Institute of Agriculture and Technology, Thuraiyur, Tamil Nadu, India \\ *Corresponding author: arivel2004@gmail.com
}

\begin{abstract}
Changes in food consumption and expenditures of households in developing country have been a topic for research throughout the twentieth century. Consumption expenditure patterns and estimates of expenditure elasticities can give an indication of the potential for demand-led growth in a particular economy and also helps in assessing the food security-related policy issues. This study uses the recent household survey data of NSSO (round 68) to estimate a complete demand system for Cauvery Delta Zone (CDZ) of Tamil Nadu State, with special emphasis on the food commodity group. A Quadratic Almost Ideal Demand System (QUAIDS) specification was employed for this study. The QUAIDS model is an example of the empirical demand systems that have been developed to allow expenditure nonlinearity. Price and expenditure elasticities were computed for seven food aggregates which includes cereals, pulses, milk, edible oil, meat, fruits and vegetables and other foods. The results revealed that the most of food groups considered for this study were demand inelastic implies that they are staple foods and the magnitude of the cross-price elasticities suggesting the limited possibilities of substitution among food groups. The estimated expenditure elasticities suggested that the expenditure share on these food groups would increase with an increase in real income, prices held constant. Overall, the findings of this study suggest that the QUAIDS model which allows for more flexibility is superior to the traditional AIDS model.

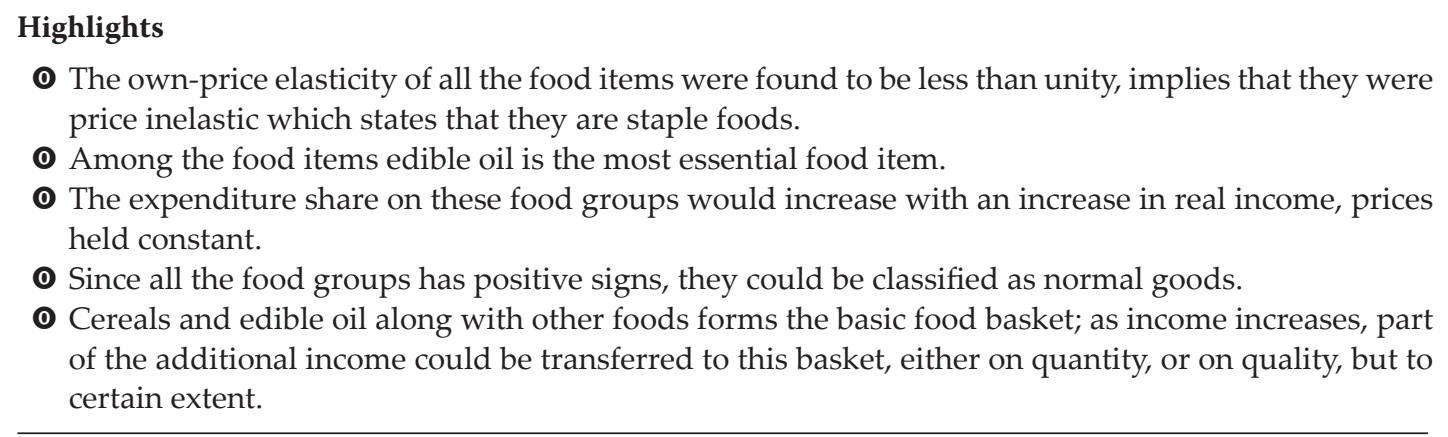

Keywords: Consumption behaviour, QUAIDS, expenditure elasticity, food security

Since post-economic reforms, India not only experienced rapid economic transformation but also substantial changes in other dimensions of well-being, including in its consumption pattern (Ali 2007). Changes in food consumption and expenditures of households in developing country have been a topic for research throughout the twentieth century. Consumption expenditure patterns and estimates of expenditure elasticities can give an indication of the potential for demandled growth in a particular economy (Browne et al. 2007) and also helps in assessing the food security- 
related policy issues (Mittal 2010). Policy questions for which knowledge of consumer behaviour is important; to improve the nutritional status of particular individuals, households or individuals within households (Sadoulet and Janvry 1995) and it is much more complex than economic and environmental implications (Arivelarasan 2016).

Consumption behaviour can be better understood through demand system models. Since the development of almost ideal demand system (AIDS) by Deaton and Muellbauer (1980); it has been a popular functional form to model demand behaviour. Several studies have used in analysing the consumer behaviour; Ray (1982) have employed this model to study the household consumption patterns of India using household expenditure surveys, while Blanciforti and Green (1983) have applied the same to US food consumption data. Filippini (1995 a,b) employed it to study the electricity demand by time of use in Switzerland, while Abdulai et al. (1999) applied it to examine food consumption behaviour by using Indian household survey data. In recent studies, Arivelarasan et al. (2014, 2016) employed the AIDS model to study the food consumption pattern of rural households of Southern India, while Balaji et al. (2017) used it to investigate consumption behaviour of food and non-foods of Indian households.

The Almost Ideal Demand System has budget shares that are linear functions of log total expenditure, a member of PIGLOG class of demand models (Muellbauer 1976). However, in the recent past there is a growing body of literature providing evidence on the significance of allowing for nonlinearity in the budget share equations (Lewbel 1991; Banks et al. 1997). The quadratic almost ideal demand system (QUAIDS) model developed by Banks et al. (1997), which has budget shares that are quadratic in log total expenditure. The QUAIDS model is an example of the empirical demand systems that have been developed to allow expenditure nonlinearity. Allowing more flexibility could be a significant development, especially if the estimated model is intended for simulation and forecasting purposes. Blundell et al. (1993) employed a QUAIDS model to assess the importance of using microlevel data in the analysis of consumer demand. Jones and Mazzi (1996) used it to analyse tobacco consumption and taxation in Italy, while Moro and
Sckokai (2000) employed it to study the household food consumption in Italy. Abdulai (2002) applied QUAIDS to the food expenditure data from Switzerland while Abdulai and Aubert (2004) examined food expenditure data of Tanzania.

\section{METERAILS AND METHODS}

The estimation of the QUAIDS model requires data on budget shares of food items and their corresponding prices. Data on expenditure on pulses, cereal, milk, meats, edible oil, fruits and vegetables, other foods (which includes beverages, drinks, spices and condiments) were obtained from national household sample surveys conducted by the National Sample Survey Organisation (NSSO) of India. This paper uses household unit level data of the $68^{\text {th }}$ round (2011-12) of NSS for the analysis. It provides household data in terms of quantity and value of commodities by rural-urban locations, states and by districts. The data refer to the average per capita consumption over the 30 day recall in each of the expenditure classes. The data are disaggregated with the level of individual crops, food items, total consumer expenditure, family size and districts. All the food items were grouped into seven food groups. The seven food aggregates included: cereals, pulses, milk, edible oil, meat, fruits and vegetables and other foods. The "other foods" group comprised of salt, sugar and spices. The primary advantage of grouping food items is that it reduces the total number of parameters in the model, thus making demand system estimation more manageable. This study accounts the major districts of Cauvery delta (i.e. Thanjavur, Thiruvarur, Nagapattinam and Thirichirapalli) of Tamil Nadu. The number observation of NSS pertains to those districts was 750 , hence the sample size of this study is 750 . The budget shares of food items were obtained by dividing household expenditure on a particular commodity group by total household expenditure.

\section{The QUAIDS Model}

In the present study, we have employed the Quadratic Almost Ideal Demand System (QUAIDS) model which was developed by Banks et al. (1997) to describe consumer behaviour. The QUAIDS is derived from a generalisation of the PIGLOG preferences based an indirect utility function of the form: 


$$
\ln V=\left\{\left[\frac{\ln m-\ln a(p)}{b(p)}\right]^{-1}+\lambda(p)\right\}^{-1}
$$

where, the term $\ln m-\ln a(p) / b(p)$ is the indirect utility function of the PIGLOG demand system, $m$ indicates household income, and $a(p), b(p)$ and $\lambda(p)$ are functions of the vector of prices $p$. To ensure the homogeneity property of the indirect utility function, it is required that $a(p)$ is homogenous of degree one in $p$, and $b(p)$ and $\lambda(p)$ are homogenous of degree zero in $p$.

The $\ln a(p)$ given in equation (1) has the usual translog form.

$$
\ln a(p)=\alpha_{0}+\sum_{j} \alpha_{j} \ln p_{j}+\frac{1}{2} \sum_{i} \sum_{j} \gamma_{i j} \ln p_{i} \ln p_{j} \ldots
$$

and $b(p)$ is the simple Cobb-Douglas price aggregator defined as,

$$
b(p)=\prod_{i=1}^{n} p_{i}^{\beta_{i}}
$$

$\lambda(p)$ is defined as,

$$
\lambda(p)=\sum_{i=1}^{n} \lambda_{i} \ln p_{i}
$$

Where $\Sigma_{i} \lambda_{i}=0$, by applying Roy's identity to the indirect utility function, the budget shares in the QUAIDS is given as,

$$
\begin{gathered}
\omega_{i}=\alpha_{i}+\sum_{j=1}^{n} \gamma_{i j} \ln p_{j}+\beta_{i}\left[\frac{m}{a(p)}\right]+\frac{\lambda_{i}}{b(p)} \\
\left\{\ln \left[\frac{m}{a(p)}\right]\right\}^{2}
\end{gathered}
$$

For theoretical consistency and to reduce the number of parameters to be estimated, it is common to impose additivity, homogeneity and symmetry restrictions. The formulae for the elasticities in the QUAIDS are given by Banks et al. (1997). They are obtained by first differentiating equation (5) with respect to $\ln m$ and $\ln p_{j^{\prime}}$, respectively, to obtain,

$$
\mu_{i}=\frac{\partial \omega_{i}}{\partial \ln m}=\beta_{i}+\frac{2 \lambda_{i}}{b(p)}\left\{\operatorname{lm}\left[\frac{m}{a(p)}\right]\right\}
$$

$$
\begin{aligned}
\mu_{i j}= & \frac{\partial \omega_{i}}{\partial \ln p_{j}}=\gamma_{i j}-\mu_{i}\left(\alpha_{j}+\sum_{k} \gamma_{j k} \ln p_{k}\right) \\
& -\frac{\lambda_{i} \beta_{j}}{b(p)}\left\{\ln \left[\frac{m}{a(p)}\right]\right\}^{2}
\end{aligned}
$$

The expenditure elasticities are then derived as $e_{i}=$ $\mu_{i} / \omega_{i}+1$. The uncompensated or Marshallian price elasticities are given by $e_{i j}{ }^{u}=\mu_{i} / \omega_{i}-\delta_{i j^{\prime}}$ where $\delta_{i j}$ is the kronecker delta, which is equal to one when $i=j$, otherwise $\delta_{i j}=0$. Using the Slutsky equation, $e_{i j}{ }^{c}=e_{i j}{ }^{u}$ $+\omega_{j} e_{i}$ the compensated or Hicksian price elasticities can be calculated and used to assess the symmetry and negativity conditions by examining the matrix with elements $\omega_{i}\left[e_{i j}^{c}\right]$ which should be symmetric and negative semi-definite in the usual way.

\section{RESULTS AND DISCUSSION}

The QUAIDS model is estimated using maximum likelihood (ML), with theoretical restrictions of adding-up, homogeneity, and symmetry imposed during estimation. The parameter estimates of the QUAIDS model presented in Table 1. It is consistently observed that for all estimated equations, both the own- and cross-price parameters are statistically significant. All expenditure parameters are also significant at the $5 \%$ level. The quadratic expenditure term is statistically significant for rice, wheat, black gram, milk, meat and fruits and vegetables of the expenditure share equations, which revealed that the expenditure share on those food items would increase with an increase in real income (total expenditure) while price held constant. Of these except milk, of all other food items the expenditure coefficients are positive. Hence, the nature of demand could be directly inferred from the signs of the QUAIDS parameters, the commodities with negative expenditure parameter were income inelastic and those with positive sign were income elastic. In a similar fashion, positive price coefficients suggest increase in expenditure on particular group in response to increase in prices of own and other commodities and vice versa.

The interpretation of price and income effects is best discussed in terms of elasticities. The magnitude of elasticities chiefly depends on the methodology employed; using the QUAIDS model the price and expenditure elasticity were computed at mean level for 2011-12. Both compensated and uncompensated 
Table 1: Estimated Coefficients of the Quadratic Almost Ideal Demand Systems (QUAIDS)

\begin{tabular}{|c|c|c|c|c|c|c|c|}
\hline Paresti & CEREALS & PULSES & MILK & EOIL & MEAT & FRTVEG & OFOODS \\
\hline$\alpha_{i 0}$ & $0.5000(0.0806)$ & $-0.0910(0.0517)$ & $0.6623(0.0917)$ & $-0.0318(0.0305)$ & ) $-0.0476(0.0510)$ & $0.0259(0.0586)$ & $-0.0179(0.0409)$ \\
\hline$\alpha_{i 1}$ & $0.1091(0.0063)$ & & & & & & \\
\hline$\alpha_{i 2}$ & $-0.0165(0.0080)$ & $0.0320(0.0093)$ & & & & & \\
\hline$\alpha_{i 3}$ & $0.0068(0.0251)$ & $0.0579(0.0135)$ & $-0.1781(0.0368)$ & & & & \\
\hline$\alpha_{i 4}$ & $-0.0232(0.0038)$ & $-0.0261(0.0042)$ & $0.0252(0.0088)$ & 0.0520 & & & \\
\hline$\alpha_{i 5}$ & $-0.0062(0.0028)$ & $-0.0030(0.0055)$ & $0.0084(0.0176)$ & $-0.0023(0.0025)$ & ) 0.0060 (0.0032) & & \\
\hline$\alpha_{i 6}$ & $-0.0198(0.0060)$ & $-0.0156(0.0078)$ & $0.0508(0.0263)$ & $-0.0081(0.0039)$ & ) $-0.0018(0.0044)$ & $0.0004(0.0114)$ & \\
\hline$\alpha_{i 7}$ & $-0.0501(0.0047)$ & $-0.0288(0.0056)$ & $0.0290(0.0132)$ & $-0.0175(0.0032)$ & ) $-0.0010(0.0031)$ & $-0.0059(0.0052)$ & $0.0743(0.0058)$ \\
\hline$\beta_{i}$ & $0.0266(0.0322)$ & $0.0811(0.0174)$ & $-0.2574(0.0214)$ & $0.0369(0.0114)$ & $0.0093(0.0217)$ & $0.0589(0.0298)$ & $0.0446(0.0161)$ \\
\hline
\end{tabular}

Note: EOIL refers edible oil, FRTVEG refers fruits and vegetables and OFOODS refers other foods, values given in the parenthesis are standard error.

Table 2: Price and Expenditure Elasticity Estimates from QUAIDS Model

\begin{tabular}{cccccccc}
\hline & CEREALS & PULSES & MILK & EOIL & MEAT & FRTVEG & OFOODS \\
\hline Uncompensated & & & & & & & \\
\hline CEREALS & -0.4339 & -0.0307 & -0.0340 & -0.0783 & -0.0260 & -0.0321 & -0.1835 \\
PULSES & -0.1184 & -0.4070 & -0.0691 & -0.1944 & -0.0076 & -0.0152 & -0.2043 \\
MILK & -0.0924 & -0.0359 & -0.8706 & -0.0243 & 0.0061 & 0.0173 & -0.0406 \\
EOIL & -0.2996 & -0.2649 & -0.0489 & -0.0983 & -0.0210 & -0.0091 & -0.1879 \\
MEAT & -0.1732 & -0.0365 & -0.0564 & -0.0399 & -0.9473 & -0.0796 & -0.0581 \\
FRTVEG & -0.0708 & -0.0042 & 0.0245 & -0.0063 & -0.0007 & -0.9427 & 0.0125 \\
OFOODS & -0.3427 & -0.1346 & -0.0349 & -0.0929 & 0.0014 & 0.0340 & -0.3459 \\
\hline Compensated & & & & & & & \\
\hline CEREALS & -0.2539 & 0.0411 & 0.1120 & -0.0270 & 0.0761 & 0.1327 & -0.0809 \\
PULSES & 0.1049 & -0.3178 & 0.1122 & -0.1308 & 0.1191 & 0.1893 & -0.0770 \\
MILK & 0.1364 & 0.0554 & -0.6850 & 0.0409 & 0.1358 & 0.2267 & 0.0899 \\
EOIL & -0.0952 & -0.1834 & 0.1170 & -0.0400 & 0.0949 & 0.1781 & -0.0713 \\
MEAT & 0.1326 & 0.0856 & 0.1917 & 0.0473 & -0.7739 & 0.2004 & 0.1163 \\
FRTVEG & 0.1464 & 0.0824 & 0.2007 & 0.0556 & 0.1224 & -0.7439 & 0.1363 \\
OFOODS & -0.1414 & -0.0542 & 0.1285 & -0.0355 & 0.1156 & 0.2183 & -0.2311 \\
\hline
\end{tabular}

price elasticities are computed and are given in Table. The uncompensated elasticity capturing both price effect and income effect, while the compensated elasticity captures only the price effect. It could be seen from the table that the negativity property is satisfied, since all own-price effects are negative. The uncompensated price elasticities show that own-price elasticities ranged between -0.0983 and -0.9473 . The own-price elasticity of all the food items were found to be less than unity, implies that they were price inelastic which states that they are staple foods. Among the food items edible oil is the most essential food item, hence its response to price change is the least $(-0.0983)$ among all and it was followed by other foods (-0.3459).
Not surprising, meat has the highest (absolutely) own price elasticity (-0.9473) followed by fruits and vegetables (-0.9427).

Since the compensated price elasticities provides more accurate picture of cross-price substitution between food items, they are measure of substitution effects of net income. In the matrix of the compensated price elasticities, it can be observed that own price effects are relatively smaller (absolutely) than the uncompensated elasticities. The fact that the signs of some compensated elasticities are different from those of the uncompensated elasticities implies that the expenditure effects significantly influence the consumer demand 
decisions. It was observed that most of the crossprice elasticities are positive, signifying that the relevant food groups are substitutes. However, their low magnitudes implies that the substitution possibilities are quite limited. It is also found that there are complementarity between food groups; cereals and edible oils, cereals and other food items, pulses and edible oils and pulses and other foods.

Table 3: Expenditure elasticity, Expenditure shares, and Marginal expenditure shares of various food items

\begin{tabular}{cccc}
\hline \multirow{2}{*}{$\begin{array}{c}\text { Food } \\
\text { groups }\end{array}$} & $\begin{array}{c}\text { Expenditure } \\
\text { elasticity }\end{array}$ & $\begin{array}{c}\text { Expenditure } \\
\text { share }\end{array}$ & $\begin{array}{c}\text { Marginal } \\
\text { expenditure } \\
\text { share }\end{array}$ \\
\cline { 3 - 4 } & & \multicolumn{2}{c}{ percentage } \\
\hline CEREALS & 0.82 & 22.08 & 18.08 \\
PULSES & 1.02 & 8.82 & 8.96 \\
MILK & 1.04 & 18.80 & 19.56 \\
EOIL & 0.93 & 6.26 & 5.82 \\
MEAT & 1.39 & 13.35 & 18.56 \\
FRTVEG & 0.99 & 19.19 & 18.95 \\
OFOODS & 0.92 & 11.50 & 10.53 \\
\hline
\end{tabular}

The estimated expenditure elasticity of the food groups are presented in Table 3. It was observed that the estimated expenditure elasticities are positive and significant for all the food groups, as would be expected. This implied that the expenditure share on these food groups would increase with an increase in real income, prices held constant. Since all the food groups has positive signs, they could be classified as normal goods. As expected, the estimated expenditure elasticities for milk, meat and pulses are more than unity. Such response towards certain food groups could partly be attributed to the nature of food consumption. As mentioned, cereals and edible oil along with other foods forms the basic food basket. As income increases, part of the additional income could be transferred to this basket, either on quantity, or on quality, but to certain extent. Additional expenditure could not be made on, thus transferred to high valued food groups (i.e. milk, meat, pulses, fruits and vegetables).

In order to estimate the marginal expenditure shares, we have adopted an approach that has been proposed by Powell (1974). The marginal expenditure share is the product of estimated expenditure elasticities and its corresponding expenditure share. The results revealed that for any increase in future expenditures, the largest percentage increase will be allocated to milk, fruits and vegetables, meat, cereals, other foods, pulses and edible oil, in that order. It was observed that the marginal share of edible oil is comparatively small, suggesting that a smaller percentage of expenditure will be allocated to future edible oil consumption, given an increase in incomes of households.

\section{CONCLUSION}

Consumption expenditure patterns and estimates of expenditure elasticities helps in assessing the food security-related policy issues. This study uses the recent household survey data of NSSO (round 68) to estimate a complete demand system for Cauvery delta zone, with special emphasis on the food commodity group. A Quadratic Almost Ideal Demand System (QUAIDS) specification was employed for this study. The QUAIDS model is an example of the empirical demand systems that have been developed to allow expenditure nonlinearity. Allowing more flexibility could be a significant development, especially if the estimated model is intended for simulation and forecasting purposes. The quadratic terms in the QUAIDS were found to be empirically important in describing household budget behaviour. Price and expenditure elasticities were computed for seven food aggregates which include cereals, pulses, milk, edible oil, meat, fruits and vegetables and other foods. The food consumption behaviour is revealed from the complete matrix of price and expenditure elasticities. The presence of significant price effects on budget-share equations for all food groups revealed that price policy is an important agricultural policy instrument.

For most of the food groups, demand is inelastic impling that they are staple foods, with elasticities ranging between -0.0983 and -0.9473 . Cross-price elasticities were quite low, suggesting limited possibilities of substitution. It is also observed that there are complementarity between food groups; cereals and edible oils, cereals and other food items, pulses and edible oils and pulses and other foods. The estimated expenditure elasticities suggested that the expenditure share on these food groups would increase with an increase in real income, prices held constant. Overall, the findings of this 


\section{C) Arivelarsan and Sekar}

study suggest that the QUAIDS model which allows for more flexibility is superior to the traditional AIDS model.

\section{REFERENCES}

Abdulai, A., Jain, D.K. and Sharma, A.K. 1999. Household Food Demand Analysis in India. J. Agric. Econ., 50(2): 316-327

Abdulai, A. and Aubert, D. 2004. A Cross-Section Analysis of Household Demand for Food and Nutrients in Tanzania. Agric. Econ., 31(1): 67-79.

Abdulai, A. 2002. Household Demand for Food in Switzerland. A Quadratic Almost Ideal Demand System. Swiss Journal of Economics and Statistics, 138: 1-18.

Ali, J. 2007. Structural Changes in Food Consumption and Nutritional Intake from Livestock Products in India. South Asia Research, 27(2): 137-151.

Arivelarasan, T., Chinnadurai, M. and Swaminathan, B. 2014. Status of Food Security among the Vulnerable Sections of Rural Households: An Application of Almost Ideal Demand System (AIDS) Model. Trends in Biosciences., 7(20): 3325-3330.

Arivelarasan, T., Jenny, K. and Latikadevi, Y. 2016. Behavioural Approach to Food Security: A Micro Level Study from Southern Part of India. Advances in life Sciences, 5(21): 9763-9766.

Balaji, S.J., Arivelarasan, T., Surendran, A. and Anbukkani, P. 2017. Pattern, Expenditure and Inequality in Food and Non-Food Consumption among Rural Households-A Micro Level Study in Tamil Nadu. Ind. J. Econ. and Dev., 13(1): 105-110.

Banks, J., Blundell, R. and Lewbel, A. 1997. Quadratic Engel Curves and Consumer Demand. Rev. of Econ. and Stat., 79: 527-539.

Blanciforti, L. and Green, R. 1983. An Almost Ideal Demand System Incorporating Habits: An Analysis of Expenditures on Food and Aggregate Commodity Group. Review of Econ. and Stat., 65(3): 511-515.
Blundell, R., Pashardes, P. and Weber, G. 1993. What Do We Learn About Consumer Demand Patterns from Micro Data?. Ame. Econ. Rev., 83: 570-597.

Browne, M., Ortmann, G.F. and Hendriks, S. 2007. Expenditure elasticities for rural Households in the Embo ward. Umbumbulu, KwaZulu-Nata, Agrekon, 46(4).

Deaton, A.S. and Muellbauer, J. 1980. An Almost Ideal Demand System. American Economic Review, 70(3): 359-368

Filippini, M. 1995a. Electricity Demand by Time of Use. An Application of the Household AIDS model. Energy. Econ., 17: 197-204.

Filippini, M. 1995b. Swiss Residential Demand for Electricity by Time-of-Use: An Application of the Almost Ideal Demand System. The Energy J., 16: 27-39.

Jones, A. and Mazzi, M.G. 1996. Tobacco Consumption and Taxation in Italy: An Application of the QUAIDS model. Appl. Econ., 28: 595-603.

Lewbel, A. 1991. The Rank of Demand Systems: Theory and Non-parametric Estimation. Econometrica, 59: 711-730.

Mittal, S. 2010. Application of the QUAIDS Model to The Food Sector in India. J. Quant. Econ., 8(1).

Moro, D. and Sckokai, P. 2000. Heterogenous Preferences in Household Food Consumption in Italy. Eur. Rev. Agri. Econ., 27(3): 305-323.

Muellbauer, J. 1976. Community Preferences and the Representative Consumer. Econometrica, 44: 525-543.

Ray, R. 1982. The Testing and Estimation of Complete Demand Surveys on Household Budget Surveys - An Application of AIDS. Eur. Econ. Rev., 17: 349-369.

Sadoulet, E. and Janvry, A. 1995. Demand Analysis in Quantitative Development Policy Analysis, Baltimore and London. The Johns Hopkins University Press. 